\title{
ПРОТРОМБОГЕННЫЕ ПОЛИМОРФНЫЕ ВАРИАНТЫ ГЕНОВ СИСТЕМЫ ГЕМОСТАЗА И ФОЛАТНОГО ОБМЕНА ПРИ АСЕПТИЧЕСКОМ ТРОМБОЗЕ ЦЕРЕБРАЛЬНЫХ ВЕНОЗНЫХ СИНУСОВ
}

М. Ю. Максимова $\bowtie$, Ю. И. Дубовицкая, М. В. Кротенкова, А. А. Шабалина

Научный центр неврологии, Москва, Россия

Тромбоз церебральных венозных синусов (ТЦВС) составляет менее 1\% всех случаев инсульта. В 20-30\% случаев причина тромбоза остается неясной и его расценивают как идиопатический. Врожденные гиперкоагуляционные состояния значительно увеличивают риск развития ТЦВС. Целью исследования было оценить частоту аллелей и генотипов протромбогенных полиморфных вариантов генов гемостаза и метионин-гомоцистеинового обмена при асептическом ТЦВС. Обследован 51 пациент с асептическим ТЦВС в возрасте от 18 до 75 лет. Контрольную группу составили 36 здоровых добровольцев. Нейровизуализационные методы включали MPT головного мозга в стандартных режимах (T1, T2, T2 d-f (FLAIR), ДВИ) и MPвеносинусографию. Всем пациентам проводили исследование на носительство аллелей и генотипов протромбогенных полиморфных вариантов генов системы гемостаза и фолатного обмена. Протромбогенные полиморфные варианты генов системы гемостаза были выявлены в 94\% случаев, генов метионин-гомоцистеинового обмена - в 86\% случаев. Получены достоверные различия при исследовании распределения аллелей и генотипов 5G6754G гена PAl-1, G103T гена FXIIIA1, A66G гена MTRR, A2756G гена MTR в группе больных ТЦВС по сравнению с группой здоровых добровольцев. Аллель 4G, генотипы 4G/4G и 5G/4G полиморфизма 5G6754G гена PAl-1; аллель Т полиморфизма G103Т гена FXIIIA1; аллель G и генотип A/G полиморфизма A66G гена MTRR; аллель G и генотип AVG полиморфизма A2756G гена MTR связаны с развитием асептического ТЦВС. Сделан вывод, что носительство полиморфизма генов PAl-1 (5G6754G), FXIIIA1 (G103T), MTRR (A66G) и MTR (A2756G) повышает риск развития асептического TЦВC и не влияет на клинические проявления тромбоза.

Ключевые слова: асептический тромбоз церебральных венозных синусов, протромбогенные полиморфные варианты генов гемостаза и фолатного обмена

Финансирование: работа выполнена в рамках государственного задания ФГБНУ НЦН

Информация о вкладе авторов: М. Ю. Максимова - разработка концепции и организация исследования, обобщающий анализ клинических и лабораторных данных, статистическая обработка, написание статьи; Ю. И. Дубовицкая - проведение клинического обследования пациентов, сбор и первичный анализ полученных результатов; М. В. Кротенкова — проведение МРТ головного мозга, МР-веносинусограсии и нейровизуализационной диагностики тромбоза церебральных венозных синусов; А. А. Шабалина — проведение лабораторного исследования протромбогенных полиморфных вариантов генов гемостаза и фолатного обмена.

Соблюдение этических стандартов: исследование одобрено этическим комитетом ФГБНУ «Научный центр неврологии» (протокол № 12-8/16 от 14 декабря 2016 г.). Все пациенты подписали добровольное информированное согласие на участие в исследовании.

$\bowtie$ Для корреспонденции: Марина Юрьевна Максимова

Волоколамское ш., д. 80, г. Москва, 125367; ncnmaximova@mail.ru

Статья получена: 19.08.2019 Статья принята к печати: 06.10.2019 Опубликована онлайн: 16.10.2019

DOI: $10.24075 /$ vrgmu.2019.065

\section{PROTHROMBOGENIC POLYMORPHIC VARIANTS OF HEMOSTATIC AND FOLATE METABOLISM GENES IN PATIENTS WITH ASEPTIC CEREBRAL VENOUS THROMBOSIS}

Maksimova MYu 凶, Dubovitskaya Yul, Krotenkova MV, Shabalina AA

Research Center of Neurology, Moscow, Russia

Cerebral venous sinus thrombosis (CVT) becomes the cause of stroke in less than $1 \%$ of patients. In $20-30 \%$ of patients, the cause of thrombosis remains unclear, and thrombosis is considered idiopathic. Inherited hypercoagulable conditions significantly increase the risk of CVT. The aim of the study was to evaluate the frequency of prothrombogenic polymorphic variants of hemostatic and methionine-homocysteine metabolism genes alleles and genotypes in patients with aseptic CVT. Fifty one patients aged 18-75 with aseptic CVT were examined. The control group included 36 healthy volunteers. Neuroimaging methods included brain $\mathrm{MRI}$ in standard modes (T1, T2, T2 d-f (FLAIR), DWI) and MR venosinusography. All patients were surveyed to identify carriers of prothrombogenic polymorphic variants of hemostatic and folate metabolism genes alleles and genotypes. Prothrombogenic polymorphic variants of hemostatic genes were detected in $94 \%$ of patients, and the variants of the methionine-homocysteine metabolism genes were observed in $86 \%$ of patients. The differences between distributions of alleles and genotypes 5G6754G of the PAl-1 gene, G103T of the FXIIIA1 gene, A66G of the MTRR gene, A2756G of the MTR gene in the group of patients with CVT and in the control group were significant. Allele 4G, genotypes $4 \mathrm{G} / 4 \mathrm{G}$ and 5G/4G of 5G6754G polymorphism of the PAl-1 gene; allele T of G103T polymorphism of the FXIIIA1 gene; allele $G$ and genotype A/G of A66G polymorphism of the MTRR gene; allele $G$ and genotype A/G of A2756G polymorphism of the MTR gene correlated with aseptic CVT. It was concluded that the gene polymorphisms 5G6754G (PAl-1), G103T (FXIIIA1), A66G (MTRR) and A2756G (MTR) carriage increased the risk of aseptic CVT and did not affect the thrombosis clinical manifestations.

Keywords: aseptic cerebral venous sinus thrombosis, prothrombogenic polymorphic variants of hemostatic and folate metabolism genes

Funding: the study was performed as a part of the public assignment of the Research Center of Neurology.

Author contribution: Maksimova MYu — concept development and study arrangement, clinical and laboratory data analysis, statistical analysis, manuscript writing; Dubovitskaya Yul — clinical examination of patients, data aquisition and primary analysis of the results; Krotenkova MV — brain MRI, MR venography and neuroimaging diagnosis of cerebral venous sinus thrombosis; Shabalina AA — laboratory analysis of prothrombogenic polymorphic variants of hemostatic and folate metabolism genes.

Compliance with ethical standards: the study was approved by the Ethics Committee of the Research Center of Neurology (protocol № 12-8/16 dated December 14, 2016). All patients submitted the informed consent to participation in the study.

Correspondence should be addressed: Marina Yu. Maximova

Volokolamskoye Shosse, 80, Moscow, 125367; ncnmaximova@mail.ru

Received: 19.08.2019 Accepted: 06.10.2019 Published online: 16.10.2019

DOI: 10.24075/brsmu.2019.065 
Тромбоз церебральных венозных синусов (ТЦВС) составляет менее 1\% всех случаев инсульта [1, 2]. В 20-30\% случаев причина тромбоза остается неясной и его расценивают как идиопатический [3]. Врожденные гиперкоагуляционные состояния значительно увеличивают риск развития ТЦВС $[4,5]$.

Частота тромбоза церебральных венозных синусов (ТЦВС) составляет 1,3 случая на 100000 взрослого населения в год. Заболевание возможно в любом возрасте, однако наиболее высокую заболеваемость отмечают у лиц 31-50 лет [6]. Среди пациентов преобладают женщины [7]. Летальность при ТЦВС, несмотря на улучшение методов диагностики и лечения, остается высокой и достигает 30\% [8].

ТЦВС может иметь либо септический характер (в результате осложнения гнойного отита, мастоидита, синусита), либо асептический (возникает как осложнение многочисленных заболеваний, усиливающих склонность к образованию тромба).

В развитии асептического ТЦВС участвуют многие факторы - тяжелая дегидратация, заболевания сердца (врожденные пороки сердца, сердечная недостаточность, искусственный водитель ритма), злокачественные новообразования, беременность, сахарный диабет, использование гормональных средств (контрацептивов, заместительной гормональной терапии), нефротический синдром, полицитемия, эссенциальный тромбоцитоз, антифосфолипидный синдром, заболевания соединительной ткани и васкулиты (системная красная волчанка, гранулематоз Вегенера, височный артериит, болезнь Бехчета), воспалительные заболевания кишечника (болезнь Крона, язвенный колит), черепно-мозговая травма, приобретенные и наследственные нарушения гемостаза [9-12].

Наследственные тромбосилии - значимый фактор риска развития асептического ТЦВС. Наиболее изучены среди них полиморфные варианты генов фактора $V$ (Лейдена) и протромбина [13]. Так, была установлена связь риска развития ТЦВС с полиморфизмами генов фактора свертывания крови V (ОШ 4,3; 95\% ДИ - 1,5-12,3) и протромбина (ОШ 3,6; 95\% ДИ - 1,0-13,1) [14]. В другом исследовании полиморфизм гена протромбина (замена A на G в позиции 20210) обнаружен в 19\% случаев ТЦВС [15]. Установлена связь носительства Лейденской мутации с 5-кратным повышением риска развития ТЦВС [13]. На основании анализа 26 исследований по типу случай-контроль было обнаружено, что возникновение полиморфизма гена фактора свертывания крови V (Leiden/ G1691A) увеличивает риск развития ТЦВС в 2,4 раза (95\% ДИ - 1,75-3,30; р 0,00001), а полиморфизма гена протромбина (G20210A) - в 5,48 раз (95\% ДИ - 3,88-7,74; $p<0,00001)[16]$.

Значительный полиморфизм клинических проявлений, отсутствие патогномоничных симптомов, а также разнообразие вариантов начала, течения и локализаций тромбоза создают трудности для клинического распознавания ТЦВС. Существенно расширяют и дополняют возможность ранней диагностики ТЦВС методы нейровизуализации (КТ и МРT) [2, 17, 18]. В настоящее время МР-веносинусография относится К наиболее надежным и достоверным методам диагностики ТЦВС [19]. До 63\% случаев ТЦВС осложнены развитием отека мозга и образованием очагов некроза с присоединением в 37,57\% случаев геморрагического компонента [20]. В такой ситуации указанные очаги некроза не являются инфарктами, а возникают вследствие замедления венозного оттока, отека, гипоксии ткани мозга с последующим диапедезом эритроцитов и лейкоцитов через некротизированные стенки капилляров и микрососудов. К факторам, предрасполагающим к возникновению очагов некроза и гематом при ТЦВС, относят женский пол, эпилептический припадок, нарушение сознания, быстро распространяющийся тромбоз с вовлечением двух и более венозных синусов [2, 8, 20].

Нередко ТЦВС протекает стерто и обнаруживается неожиданно для лечащего врача при проведении КТ или МРТ головного мозга. Для большинства случаев ТЦВС характерно несоответствие общего состояния пациента и нейровизуализационных проявлений заболевания [17, 21].

Ранняя диагностика и правильно организованное лечение асептического ТЦВС у подавляющего большинства пациентов может привести к клиническому выздоровлению. В дальнейшем снижение частоты повторного тромбоза зависит от своевременного выявления причины его развития. Почти все исследователи, изучавшие данную проблему, согласны с тем, что повторный ТЦВС протекает тяжелее, чем впервые диагностированный, и прогноз его значительно хуже.

Целью исследования было оценить частоту аллелей и генотипов протромбогенных полиморфных вариантов генов гемостаза и метионин-гомоцистеинового обмена при асептическом ТЦВС.

\section{ПАЦИЕНТЫ И МЕТОДЫ}

В течение 2016-2019 гг. в Научном центре неврологии был обследован 51 больной с асептическим ТЦВС (20 мужчин и 31 женщина, средний возраст пациентов составил 42,2 \pm 13,1 года). 28 больных были госпитализированы в остром периоде заболевания, у 23 больных давность тромбоза составляла от 1 до 10 месяцев. В контрольную группу вошли 36 здоровых добровольцев (14 мужчин и 22 женщины; средний возраст - 44,7 $\pm 10,4)$. Исследуемые группы были сопоставимы по полу и возрасту. Критерии включения пациентов в исследование: 1) наличие острого асептического ТЦВС, подтвержденного данными нейровизуализации; 2) наличие перенесенного ранее асептического ТЦВС, подтвержденного данными нейровизуализации; 3) возраст пациентов от 18 лет до 75 лет. Критерии исключения пациентов из исследования: 1) септический характер ТЦВС; 2) тромбоз глубоких вен нижних конечностей и тромбоэмболия легочного ствола и легочных артерий; 3) атеротромбоз мозговых артерий, артерий нижних конечностей; 4) другие (несосудистые) заболевания нервной системы; 5) сопутствующие соматические заболевания в стадии декомпенсации.

У всех пациентов с ТЦВС проводили детальное изучение жалоб, данных общего и семейного анамнеза, клинической картины заболевания и медицинской документации, оценивали общесоматический и неврологический статусы.

Для диагностики ТЦВС каждому пациенту проводили MPT головного мозга на аппаратах Magnetom Verio (Siemens; Германия), Magnetom Symphony (Siemens; Германия) с величиной магнитной индукции 3 и 1,5 Тесла соответственно. МРТ головного мозга выполняли в сагиттальной, аксиальной и коронарной плоскостях в Т1, T2, Т2 d-f (FLAIR), ДВИ режимах с толщиной среза 1, 3 и 5 мм. Затем МРТ проводили в режиме веносинусографии, с помощью которого были получены изображения мозговых вен и венозных синусов. Только после комплексной оценки и детального изучения соответствия результатов нейровизуализационных исследований в стандартных 
режимах и МР-веносинусограсии диагноз ТЦВС считали подтвержденным. Стандартные режимы T2, T2-FLAIR проводили для оценки очаговых изменений ткани мозга и исключения другой возможной патологии. Изображения оценивали с помощью программы для работы с медицинскими изображениями eFilm Workstation (Merge Healthcare; США).

Исследование показателей гемостаза (уровней фибриногена, фрибринолитической активности, активированного частичного тромбопластинового времени (АЧТВ)) проводили на автоматическом коагулометре ACL9000 (Instrumentation Laboratory; США).

Количественное определение Д-димеров осуществляли иммунохимическим методом, основанным на реакции специфического взаимодействия антиген-антитело, с использованием иммунотурбидиметрического латексного теста (Instrumentation Laboratory; США).

Уровень гомоцистеина в крови определяли иммуноферментным методом с помощью диагностических наборов (AXIS; Норвегия) на иммунохемилюминесцентном анализаторе Immulite 2000 (Siemens; США).

ДНК-диагностику протромботических полиморфных вариантов генов проводили с использованием полимеразной цепной реакции (ПЦР).

Для выявления мутаций (полиморфизмов) в геноме человека использовали комплект реагентов компании «ДНК-технология» (Россия). Геномную ДНК пациента выделяли из цельной крови (пробирка с ЭДТА) с использованием реагентов для выделения ДНК (проба-НК) (ДНК-технология; Россия).

С образцом выделенной ДНК одновременно проводили две реакции амплификации - с двумя парами аллель-специфичных праймеров. Для одновременной амплификации и измерения количества искомой молекулы ДНК применяли модификацию ПЦР в режиме «реального времени» (амплификатор Real-time ДТ-Лайт; ДНК-технология; Россия). Результаты анализа были представлены тремя типами заключений: а) гомозигота по аллели 1; б) гетерозигота; в) гомозигота по аллели 2.

Перечень исследованных протромбогенных полиморфных вариантов генов системы гемостаза и фолатного обмена:

- ген протромбина — FII (c.G20210A);

- ген фактора свертывания крови V — FV (c.G1691A);

- ген фактора свертывания крови VII — FVII (c.G10976A);

- ген активированного фактора XIII (фибриназа) FXIIIA1 (c.G103T);

- ген фибриногена бета — FGB (c.G455A);

- ген ингибитора активатора плазминогена - PAl-1 (c.5G6754G);

- ген интегрина альфа (гликопротеина Gp1a) — ITGA2 (c.C807T);

- ген тромбоцитарного рецептора фиибриногена (гликопротеина Gр3a) — ITGB3 (с.T1565C);

- ген метилентетрагидрофолатредуктазы - MTHFR (c.C677T);

- ген метилентетрагидрофолатредуктазы - MTHFR (c.A1298C);

- ген метионинсинтазы - MTR (с.A2756G);

- ген метионинсинтазы редуктазы - MTRR (с.A66G).

Статистический анализ проводили с использованием программы IBM SPSS Statistics v.23 (IBM Corporation; Россия). Номинальные данные описывали с указанием абсолютных значений и процентных долей. Для анализа категориальных переменных использовали частотный анализ с построением таблиц сопряженности. Уровень значимости принимали равным 0,05 во всех сравнениях.

Частоту вариантов аллелей и генотипов ( $f$ ) вычисляли по формуле:

$$
\begin{aligned}
& f=\frac{n}{2 N}-\text { частота появления аллелей, } \\
& f=\frac{n}{N}-\text { частота появления генотипов, }
\end{aligned}
$$

где $n$ - встречаемость вариантов (аллеля или генотипа), N - объем выборки.

Достоверность различия частот появления аллелей и генотипов в исследуемых группах оценивали с использованием критерия $x^{2}$.

Для оценки величины относительного риска использовали рассчет отношения шансов (ОШ) и его доверительный интервал (ДИ) при уровне доверия 95\%.

$$
\mathrm{OШ}=\frac{(a+d)}{(b+c)},
$$

где a - частота появления исследуемого аллеля (генотипа) в основной группе; $b$ - частота появления аллеля в группе контроля; c - сумма частот появления остальных аллелей (генотипов) в основной группе; $d$ - сумма частот появления остальных аллелей (генотипов) в группе контроля.

\section{РЕЗУЛЬТАТЫ ИССЛЕДОВАНИЯ}

Изолированный ТЦВС выявлен в 14 случаях (27,5\%). В остальных 37 случаях (72,5\%) был обнаружен множественный тромбоз с вовлечением двух и более венозных синусов.

Тромбоз левого поперечного синуса был выявлен у 28 пациентов (54,9\%), левого сигмовидного синуса - у 26 (51\%), правого поперечного синуса — у 21 (41,2\%), правого сигмовидного синуса - у 14 (27,5\%), верхнего сагиттального синуса - у 11 (21,6\%), нижнего сагиттального синуса - у 4 (7,8\%), прямого синуса - у 3 (5,9\%), левого кавернозного синуса - у 1 пациента.

Среди пациентов с тромбозом отдельных венозных синусов у 5 человек $(35,7 \%)$ диагностирован тромбоз левого поперечного синуса, у 5 (35,7\%) - тромбоз левого сигмовидного синуса, у $3(21,4 \%)$ - тромбоз правого поперечного синуса, у 1 пациента - тромбоз верхнего сагиттального синуса.

У 4 женщин ТЦВС развился на фоне прерывания беременности, у 1 - через 9 дней после родов, у 7 (22,6\%) - на фоне приема гормональных препаратов (контрацептивов). Воспалительные заболевания околоносовых пазух в анамнезе наблюдали у 3 женщин и 1 мужчины. Асептический характер ТЦВС был подтвержден отсутствием системных воспалительных реакций и воспалительных изменений лабораторных показателей крови.

Среди всех пациентов с ТЦВС у 14 (27,5\%) наблюдали очаговые некротические изменения в ткани мозга, обусловленные развитием тромбоза.

Основной жалобой была диффузная головная боль - у 45 пациентов (88,2\%). Весьма характерной особенностью головной боли оказалось ее усиление после пребывания в горизонтальном положении. Несистемное головокружение отмечено у 27,5\% пациентов, оно было постоянным, не зависящим от положения тела. 
Тошнота возникала у 23,5\% пациентов. У 7 пациентов $(13,7 \%)$ тромбоз начинался с нарушения сознания. Судорожные припадки наблюдались у 5 пациентов (9,8\%): в 2 случаях - фокальные двигательные приступы, в 3 случаях - генерализованные тонико-клонические припадки. У 9,8\% пациентов возникали менингеальные симптомы. Двигательные нарушения выявлены у 3 пациентов (5,9\%): в одном случае - гемиплегия, в 2 случаях — легкое или умеренное снижение мышечной силы в конечностях Речевые нарушения были представлены моторной афазией легкой степени выраженности у 4 (7,8\%) пациентов.

При расчете коэффициентов корреляции обнаружена взаимосвязь между очаговыми изменениями ткани мозга и развитием судорожных припадков (коэффрициент корреляции $r=0,4 ; p<0,01)$, двигательных нарушений (коэффициент корреляции $r=0,5 ; p<0,01$ ), речевых нарушений (коэффициент корреляции $r=0,5 ; p<0,01$ ) и угнетением сознания (коэффициент корреляции $r=0,5$; $p<0,01)$.

Статистический анализ выявил взаимосвязь тромбоза верхнего сагиттального синуса с развитием судорожного припадка (коэффициент корреляции $r=0,4 ; p<0,01$ ) и нарушением оттока венозной крови (коэффициент корреляции $r=0,5 ; p<0,01)$, тромбоза прямого синуса с угнетением сознания (коэффициент корреляции $r=0,3$; $p<0,01$.

\section{Показатели гемостаза}

В группе больных с ТЦВС уровень фибриногена составил 3,7 г/л [2,2; 6,8] (в контрольной группе - 3,8 г/л [2,9; 5,0]); активированное частичное тромбопластиновое время 29,5 с [22,5; 36,2] (в контрольной группе 28,7 с [26,5; 29,9]); уровень антитромбина III - 112 [98; 119] (в контрольной группе - 115 [107; 126]); уровень протеина C - 134\% [125; 148] (в контрольной группе - 143\% [125; 165]); D-димер не превышал 0,5 мкг/мл. Повышение фибриногена более 5,5 ммоль/л выявлено в одном случае ТЦВС. Показатели гемостаза при ТЦВС статистически значимо не отличались от показателей контрольной группы.

Уровень гомоцистеина в плазме крови при ТЦВС составил 16,2 мкмоль/л [14,6; 17,7] (в контрольной группе $7,7[5,6 ; 10,9] ; p<0,05)$.

\section{Протромбогенные полиморфные варианты генов гемостаза и фолатного обмена}

Проведено молекулярно-генетическое тестирование на выявление протромбогенных полиморфных вариантов генов гемостаза (табл. 1) и метионин-гомоцистеинового обмена (табл. 2) у 51 больного с асептическим ТЦВС.

В гомозиготном состоянии (4G/4G) аллель 4G в -675 положении гена PAI-1 обнаружили в 11 случаях (22,4\%). Аллель 103Т гена FXIIIA1 обнаружили в гомозиготном состоянии у 3 пациентов и аллель 807Т гена ITGA2 - у 3 пациентов. Гомозиготное носительство аллеля 455А гена FGB выявлено у 2 пациентов, аллеля 10976A гена FVII у 1 пациента, аллеля 1565C гена ITGB3 - у 1 пациента. Сочетание двух аллелей в гомозиготном состоянии обнаружено в 2 случаях. В одном случае наблюдали сочетание гомозиготного носительства аллеля 10976А гена FVII и аллеля 6754G гена ингибитора активатора плазминогена PAl-1, в другом - сочетание гомозиготного носительства аллеля 103T гена FXIIIA1 и аллеля 6754G гена ингибитора активатора плазминогена PAl-1. Гомозиготное носительство аллеля 1691A гена FV Leiden и аллеля 20210A гена Fll не выявлено ни в одном случае.

Аллель 4G в -675 положении гена PAI-1 обнаружили в гетерозиготном варианте у 28 (57,1\%) пациентов. Изолированный полиморфный вариант гена PAl-1 (с. 5G6754G) в гетерозиготном состоянии наблюдали у 9 (19\%) пациентов. Гетерозиготное носительство аллеля 455A гена FGB выявлено в 17 (34,7\%) случаях; аллелей 10976А гена FVII, 103T гена FXIIIA1, 1565C гена ITGB3 — в $13(26,5 \%)$ случаях соответственно. Полиморфный вариант 807T гена ITGA2 в гетерозиготном состоянии установлен в 9 (18,4\%) случаях. Полиморфный вариант 1691А гена FV Leiden в гетерозиготном состоянии был обнаружен у 3 (5,9\%) пациентов. Гетерозиготное носительство аллеля 20210A гена Fll встречалось в 2 (4\%) случаях.

Распределение частот аллелей и генотипов протромбогенных полиморфных вариантов генов гемостаза представлено в табл. 1.

Частота аллелей 5G и 4G гена PAl-1 составила 48 (49\%) и 50 (51\%) - среди пациентов основной группы и 59 (82\%) и 13 (18\%) - среди пациентов контрольной группы. Согласно рассчитанному коэффициенту отношения шансов, аллель 4G увеличивает риск развития ТЦВС более чем в 4 раза $\left(\chi^{2}=19,337 ; p<0,001\right.$; ОШ = 4,728; 95\% ДИ - 2,303-9,706). Носительство гомозиготного полиморфизма 4G/4G повышает риск развития ТЦВС в 10,1 раз $\left(\chi^{2}=6,623 ; p=0,011\right.$; ОШ = 10,132 + 1,070; 95\% ДИ - 1,243-82,573), гетерозиготного полиморфизма $5 \mathrm{G} / 4 \mathrm{G}$ - в 3,03 раза $\left(\alpha^{2}=5,908 ; p=0,016\right.$; ОШ = 3,030 + 0,463; 95\% ДИ - 1,223-7,507).

При сравнительном анализе частот аллелей полиморфизма G103T гена FXIIIA1 у пациентов основной и контрольной групп были выявлены статистически значимые различия. Частота встречаемости аллелей $\mathrm{G}$ и Т гена FXIIIA1 составила 79 (80,6\%) и 19 (19,4\%) - в группе больных ТЦВС и 67 (93\%) и 5 (7\%) - в контрольной группе. Таким образом, частота аллеля 103Т гена FXIIIA1 у больных с ТЦВС достоверно превышает таковую в группе здоровых лиц ( $\left.\chi^{2}=5,3 ; p=0,022\right)$. Согласно рассчитанному коэффициенту отношения шансов, возникновение аллеля Т гена FXIIIA1 увеличивает риск развития ТЦВС более чем в 3 раза (ОШ = 3,223; 95\% ДИ - 1,142-9,095).

Различий в распределении частот аллелей и генотипов генов FIl (с.G20210A), FV (c.G1691A), FVII (c.G10976A), FGB (c.G455A), ITGA2 (c.C807T), ITGB3 (c.T1565C), MTHFR (с.C677T), MTHFR (с.А1298С) у больных с ТЦВС и здоровых добровольцев выявлено не было.

Среди пациентов с полиморфными вариантами генов метионин-гомоцистеинового обмена аллель 66G гена MTRR в гомозиготном состоянии выявили в 5 (10,9\%) случаях. Гомозиготное носительство аллеля 677Т гена MTHFR обнаружено в 3 (6,8\%) случаях, аллеля 1298C гена MTHFR - в 2 (4,2\%) случаях. В одном случае наблюдали сочетание гомозиготного носительства аллеля $1298 \mathrm{C}$ гена MTHFR и аллеля 66G гена MTRR. Гомозиготное носительство аллеля 2756G гена MTR не выявлено ни в одном случае.

Гетерозиготный вариант носительства аллеля 677Т гена MTHFR выявлен у 16 (36,4\%) пациентов, аллеля 66G гена MTRR - у 19 (41,3\%), аллеля $2756 \mathrm{G}$ гена MTR у 18 (39,1\%), аллеля 1298C MTHFR - у 9 (18,8\%) пациентов.

Изолированный полиморфный вариант гена MTRR (с.A66G) в гетерозиготном состоянии наблюдали у 7 (17\%) пациентов. 
У 3 (7\%) пациентов был обнаружен изолированный полиморфный вариант гена MTR (с.A2756G) в гетерозиготном состоянии.

Среди 19 пациентов с гетерозиготным носительством аллеля 66G гена MTRR у 9 (47\%) пациентов также выявлен гетерозиготный вариант аллеля 1298 С гена MTHFR.
В табл. 2 представлены показатели частот для отдельных полиморфных вариантов генов метионингомоцистеинового обмена.

Согласно полученным данным, частота аллелей $\mathrm{A}$ и $\mathrm{G}$ гена MTRR (с.A66G) в основной группе соответствовала 63 (68,5\%) и 29 (31,5\%). Частота этих аллелей в контрольной

Таблица 1. Частота аллелей и генотипов протромбогенных полиморфных вариантов генов гемостаза

\begin{tabular}{|c|c|c|c|c|c|c|}
\hline \multicolumn{7}{|c|}{ Ген протромбина FII (c.G20210A) } \\
\hline & \multirow{2}{*}{$n$} & \multicolumn{2}{|c|}{ Частота аллеля } & \multicolumn{3}{|c|}{ Частота генотипа } \\
\hline & & G & A & $\mathrm{G} / \mathrm{G}$ & $\mathrm{G} / \mathrm{A}$ & AVA \\
\hline Пациенты с ТЦВС & 50 & $98(98 \%)$ & $2(2 \%)$ & $48(96 \%)$ & $2(4 \%)$ & $0(0 \%)$ \\
\hline Контрольная группа & 36 & $71(99 \%)$ & $1(1 \%)$ & $35(97,2 \%)$ & $1(2,8 \%)$ & $0(0 \%)$ \\
\hline \multicolumn{7}{|c|}{ Ген фактора свертывания крови V - FV (c.G1691A) } \\
\hline & \multirow{2}{*}{$n$} & \multicolumn{2}{|c|}{ Частота аллеля } & \multicolumn{3}{|c|}{ Частота генотипа } \\
\hline & & $\mathrm{G}$ & A & $\mathrm{G} / \mathrm{G}$ & $\mathrm{G} / \mathrm{A}$ & A/A \\
\hline Пациенты с ТЦВС & 51 & $99(97,1 \%)$ & $3(2,9 \%)$ & $48(94,1 \%)$ & $3(5,9 \%)$ & $0(0 \%)$ \\
\hline Контрольная группа & 36 & $72(100 \%)$ & $0(0 \%)$ & $36(100 \%)$ & $0(0 \%)$ & $0(0 \%)$ \\
\hline \multicolumn{7}{|c|}{ Ген фактора свертывания крови VII - FVII (c.G10976A) } \\
\hline & \multirow{2}{*}{$n$} & \multicolumn{2}{|c|}{ Частота аллеля } & \multicolumn{3}{|c|}{ Частота генотипа } \\
\hline & & G & A & $\mathrm{G} / \mathrm{G}$ & $\mathrm{G} / \mathrm{A}$ & A/A \\
\hline Пациенты с ТЦВС & 49 & $83(84,7 \%)$ & $15(15,3 \%)$ & $35(71,4 \%)$ & $13(26,5 \%)$ & $1(2 \%)$ \\
\hline Контрольная группа & 36 & 66 (92\%) & $6(8 \%)$ & $30(83,3 \%)$ & $6(16,7 \%)$ & $0(0 \%)$ \\
\hline \multicolumn{7}{|c|}{ Ген активированного фактора XIII (фибриназы) FXIIIA1 (c.G103T) } \\
\hline & \multirow{2}{*}{$n$} & \multicolumn{2}{|c|}{ Частота аллеля } & \multicolumn{3}{|c|}{ Частота генотипа } \\
\hline & & $\mathrm{G}^{*}$ & $T^{\star *}$ & G/G & $\mathrm{G} / \mathrm{T}$ & $\mathrm{T} / \mathrm{T}$ \\
\hline Пациенты с ТЦВС & 49 & $79(80,6 \%)$ & $19(19,4 \%)$ & $33(67,3 \%)$ & $13(26,5 \%)$ & $3(6,1 \%)$ \\
\hline Контрольная группа & 36 & $67(93 \%)$ & $5(7 \%)$ & $31(86,1 \%)$ & $5(13,9 \%)$ & $0(0 \%)$ \\
\hline
\end{tabular}

Примечание: * $-\chi^{2}=5,3 ; p=0,022 ;$ ОШ =0,310; 95\% ДИ 0,110-0,876;

** $-\chi^{2}=5,3 ; p=0,022 ;$ ОШ = 3,223 + 0,529; 95\% ДИ 1,142-9,095.

\begin{tabular}{|l|c|c|c|c|c|c|}
\hline \multicolumn{5}{|c|}{ Ген ингибитора активатора плазминогена - PAl-1 (с.5G6754G) } \\
\hline & $n$ & \multicolumn{2}{|c|}{ Частота аллеля } & \multicolumn{4}{|c|}{ Частота генотипа } \\
\cline { 4 - 8 } & & $5 G^{*}$ & $4 G^{\star *}$ & $5 \mathrm{G} / 5 \mathrm{G}^{\star \star \star}$ & $5 \mathrm{G} / 4 \mathrm{G}^{\star \star \star \star}$ & $4 \mathrm{G} / 4 \mathrm{G}^{\star \star \star \star \star}$ \\
\hline Пациенты с ТЦВС & 49 & $48(49 \%)$ & $50(51 \%)$ & $10(20,4 \%)$ & $28(57,1 \%)$ & $11(22,4 \%)$ \\
\hline Контрольная группа & 36 & $59(82 \%)$ & $13(18 \%)$ & $24(66,7 \%)$ & $11(30,6 \%)$ & $1(2,8 \%)$ \\
\hline
\end{tabular}

Примечание: * $-\chi^{2}=19,337 ; p<0,001 ;$ ОШ =0,212; 95\% ДИ 0,103-0,434;

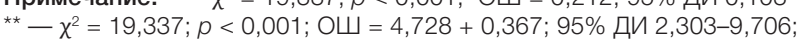

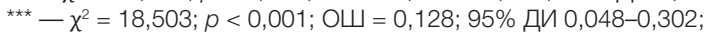

**** $-\chi^{2}=5,908 ; p=0,016 ;$ ОШ $=3,030+0,463 ; 95 \%$ ДИ 1,223-7,507;

**** $-\chi^{2}=6,623 ; p=0,011 ;$ ОШ = 10,132 +1,070; 95\% ДИ 1,243-82,573.

\begin{tabular}{|c|c|c|c|c|c|c|}
\hline \multicolumn{7}{|c|}{ Ген фибриногена бета - FGB (c.G455A) } \\
\hline & \multirow{2}{*}{$n$} & \multicolumn{2}{|c|}{ Частота аллеля } & \multicolumn{3}{|c|}{ Частота генотипа } \\
\hline & & $\mathrm{G}$ & A & $\mathrm{G} / \mathrm{G}$ & $\mathrm{G} / \mathrm{A}$ & $\mathrm{A} / \mathrm{A}$ \\
\hline Пациенты с ТЦВС & 49 & $77(78,6 \%)$ & $21(21,4 \%)$ & $30(61,2 \%)$ & $17(34,7 \%)$ & $2(4,1 \%)$ \\
\hline Контрольная группа & 36 & $62(86 \%)$ & $10(14 \%)$ & $26(72,2 \%)$ & $10(27,8 \%)$ & $0(0 \%)$ \\
\hline \multicolumn{7}{|c|}{ Ген интегрина альфа (гликопротеина Gр1a) - ITGA2 (с.C807T) } \\
\hline & \multirow{2}{*}{$n$} & \multicolumn{2}{|c|}{ Частота аллеля } & \multicolumn{3}{|c|}{ Частота генотипа } \\
\hline & & $\mathrm{C}$ & $\mathrm{T}$ & $\mathrm{C} / \mathrm{C}$ & $\mathrm{C} / \mathrm{T}$ & $\mathrm{T} / \mathrm{T}$ \\
\hline Пациенты с ТЦВС & 49 & $83(84,7 \%)$ & $15(15,3 \%)$ & $37(75,5 \%)$ & $9(18,4 \%)$ & $3(6,1 \%)$ \\
\hline Контрольная группа & 36 & $61(85 \%)$ & $11(15 \%)$ & $26(72,2 \%)$ & $9(25 \%)$ & $1(2,8 \%)$ \\
\hline \multicolumn{7}{|c|}{ Ген тромбоцитарного рецептора фибриногена (гликопротеина Gр3а) - ITGB3 (с.T1565C) } \\
\hline & \multirow{2}{*}{$n$} & \multicolumn{2}{|c|}{ Частота аллеля } & \multicolumn{3}{|c|}{ Частота генотипа } \\
\hline & & $\mathrm{T}$ & $\mathrm{C}$ & $\mathrm{T} / \mathrm{T}$ & $\mathrm{T} / \mathrm{C}$ & $\mathrm{C} / \mathrm{C}$ \\
\hline Пациенты с ТЦВС & 49 & $83(84,7 \%)$ & $15(15,3 \%)$ & $35(71,4 \%)$ & $13(26,5 \%)$ & $1(2 \%)$ \\
\hline Контрольная группа & 36 & $67(93 \%)$ & $5(7 \%)$ & $31(86,1 \%)$ & $5(13,9 \%)$ & $0(0 \%)$ \\
\hline
\end{tabular}


группе составила 64 (89\%) и 8 (11\%) соответственно. Различия по частоте встречаемости аллеля $\mathrm{G}$ в группах больных с ТЦВС и здоровых лиц были статистически достоверными $\left(\chi^{2}=9,631 ; p=0,002 ;\right.$ ОШ = 3,683; 95\% ДИ - 1,564-8,672). Аллель $\mathrm{G}$ увеличивает риск развития ТЦВС в 3,68 раза $\left(\chi^{2}=9,631 ; p=0,002 ;\right.$ ОШ = 3,683 + 0,437; 95\% ДИ - 1,564-8,672). Носительство полиморфизма AVG повышает риск развития ТЦВС в 3,5 раза $\left(\chi^{2}=5,784\right.$; $p=0,017$; ОШ = 3,519 + 0.538; 95\% ДИ - 1,225-10,104).

Частота аллеля G полиморфизма A2756G гена MTR в группе больных ТЦВС была достоверно выше, чем в контрольной группе (18 (19,6\%) против 6 (8\%); $\chi^{2}=4,079$; $p=0,044)$, а частота аллеля А - достоверно ниже $(74(80,4 \%)$ против 66 (92\%); $\left.\chi^{2}=4,079 ; p=0,044\right)$. Расчет ОШ показал, что аллель $\mathrm{G}$ полиморфизма A2756G связан с развитием ТЦВС (ОШ = 2,676 + 0,501; 95\% ДИ - 1,002-7,142). У пациентов с ТЦВС частота гетерозиготного генотипа A/G в группе пациентов с ТЦВС также была достоверно выше, чем в контрольной группе $\left(\chi^{2}=4,923 ; p=0,027\right.$; ОШ = 3,214 + 0,540; 95\% ДИ-1,116-9,257).

При проведении клинико-молекулярного анализа статистически значимых ассоциаций клинических особенностей ТЦВС с выявленными протромбогенными полиморфными вариантами генов отмечено не было.

Изолированный ТЦВС у пациентов без полиморфизмов гена PAl-1 (с.5G6754G) диагностирован в 1 случае, а при наличии полиморфизмов гена PAl-1 в гомозиготном или гетерозиготном состоянии - в 13 (33\%) случаях; множественный ТЦВС у пациентов с отсутствием полиморфизмов гена PAl-1 отмечен в 9 (90\%) случаях и полиморфными вариантами гена PA/-1 в гомозиготном и гетерозиготном состоянии - в 26 (67\%) случаях ( $p=0,244)$.

Изолированный ТЦВС при полиморфных вариантах гена FXIIIA1 (c.G103T) в гомозиготном или гетерозиготном состоянии наблюдали у 5 (31\%) пациентов, при отсутствии полиморфизмов гена FXIIIA1 - у 9 (27\%) пациентов; множественный ТЦВС выявлен у 11 (69\%) пациентов с полиморфными вариантами гена FXIIIA1 (с.G103T) в гомозиготном или гетерозиготном состоянии и в 24 (73\%) случаях при отсутствии полиморфизмов гена FXIIIA1 $(p=1,000)$.

У пациентов с полиморфным вариантом гена MTR 2756 в гетерозиготном состоянии изолированный ТЦВС встречался в 10 (56\%) случаях, а множественный тромбоз в 8 (44\%) случаях. При отсутствии полиморфизмов гена MTR (с.A2756G) изолированный ТЦВС диагностирован в 7 (25\%) случаях, а множественный - в 21 (75\%) случае $(p=0,06)$.

При гомозиготном или гетерозиготном варианте носительства аллеля 677T гена MTRR изолированный ТЦВС выявлен у 5 (21\%) пациентов, а множественный - у 19 (79\%) пациентов. Среди пациентов без полиморфизма гена MTRR изолированный ТЦВС диагностирован в 8 (38\%) случаях, а множественный — в 13 (62\%) случаях $(p=0,323)$.

\section{ОБСУЖДЕНИЕ РЕЗУЛЬТАТОВ}

В проведенном исследовании у 24 пациентов $(47,1 \%)$ ТЦВС был диагностирован в возрасте до 40 лет. Соотношение

Таблица 2. Частота аллелей и генотипов протромбогенных полиморфных вариантов генов фолатного обмена

\begin{tabular}{|c|c|c|c|c|c|c|}
\hline \multicolumn{7}{|c|}{ Ген метилентетрагидрофолатредуктазы - MTHFR (с.C677T) } \\
\hline & \multirow{2}{*}{$n$} & \multicolumn{2}{|c|}{ Частота аллеля } & \multicolumn{3}{|c|}{ Частота генотипа } \\
\hline & & $\mathrm{C}$ & $\mathrm{T}$ & $\mathrm{C} / \mathrm{C}$ & $\mathrm{C} / \mathrm{T}$ & $\mathrm{T} / \mathrm{T}$ \\
\hline Пациенты с ТЦВС & 44 & $66(75 \%)$ & $22(25 \%)$ & $25(56,8 \%)$ & $16(36,4 \%)$ & $3(6,8 \%)$ \\
\hline Контрольная группа & 36 & $60(83 \%)$ & $12(17 \%)$ & $26(72,2 \%)$ & $8(22,2 \%)$ & $2(5,6 \%)$ \\
\hline \multicolumn{7}{|c|}{ Ген метилентетрагидрофолатредуктазы - MTHFR (с.А1298C) } \\
\hline & \multirow{2}{*}{$n$} & \multicolumn{2}{|c|}{ Частота аллеля } & \multicolumn{3}{|c|}{ Частота генотипа } \\
\hline & & A & $\mathrm{C}$ & $A / A$ & $\mathrm{~A} / \mathrm{C}$ & $\mathrm{C} / \mathrm{C}$ \\
\hline Пациенты с ТЦВС & 48 & $83(86,5 \%)$ & $13(13,5 \%)$ & $37(77,1 \%)$ & $9(18,8 \%)$ & $2(4,2 \%)$ \\
\hline Контрольная группа & 36 & $64(89 \%)$ & $8(11 \%)$ & $29(80,6 \%)$ & $6(16,7 \%)$ & $1(2,8 \%)$ \\
\hline \multicolumn{7}{|c|}{ Ген метионинсинтазы редуктазы - MTRR (с.A66G) } \\
\hline & \multirow{2}{*}{$n$} & \multicolumn{2}{|c|}{ Частота аллеля } & \multicolumn{3}{|c|}{ Частота генотипа } \\
\hline & & $A^{*}$ & $\mathrm{G}^{\star \star}$ & $\mathrm{A} / \mathrm{A}^{\star \star *}$ & $\mathrm{~A} / \mathrm{G}^{\star \star \star \star}$ & $\mathrm{G} / \mathrm{G}$ \\
\hline Пациенты с ТЦВС & 46 & $63(68,5 \%)$ & $29(31,5 \%)$ & $22(47,8 \%)$ & $19(41,3 \%)$ & $5(10,9 \%)$ \\
\hline Контрольная группа & 36 & $64(89 \%)$ & $8(11 \%)$ & $29(80,6 \%)$ & $6(16,7 \%)$ & $1(2,8 \%)$ \\
\hline
\end{tabular}

Примечание: * $-\chi^{2}=9,631 ; p=0,002 ;$ ОШ =0,272; 95\% ДИ 0,115-0,640;

** $-\chi^{2}=9,631 ; p=0,002 ;$ ОШ = 3,683 + 0,437; 95\% ДИ 1,564-8,672;

*** - $\chi^{2}=9,201 ; p=0,003 ;$ ОШ = 0,221; 95\% ДИ 0,081-0,606;

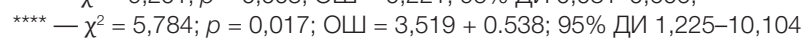

\begin{tabular}{|c|c|c|c|c|c|c|}
\hline \multicolumn{7}{|c|}{ Ген метионинсинтазы - MTR (c.A2756G) } \\
\hline & \multirow{2}{*}{$n$} & \multicolumn{2}{|c|}{ Частота аллеля } & \multicolumn{3}{|c|}{ Частота генотипа } \\
\hline & & $A^{*}$ & $\mathrm{G}^{\star *}$ & $\mathrm{~A} / \mathrm{A}^{\star \star \star}$ & $\mathrm{A} / \mathrm{G}^{\star \star \star \star}$ & $\mathrm{G} / \mathrm{G}$ \\
\hline Пациенты с ТЦВС & 46 & $74(80,4 \%)$ & $18(19,6 \%)$ & $28(69,9 \%)$ & $18(39,1 \%)$ & $0(0 \%)$ \\
\hline Контрольная группа & 36 & $66(92 \%)$ & $6(8 \%)$ & $30(83,3 \%)$ & $6(16,7 \%)$ & $0(0 \%)$ \\
\hline
\end{tabular}

Примечание: *- $\chi^{2}=4,079 ; p=0,044 ;$ ОШ = 0,374; 95\% ДИ 0,140-0,998;

${ }^{* \star}-\chi^{2}=4,079 ; p=0,044 ;$ ОШ $=2,676+0,501 ; 95 \%$ ДИ 1,002-7,142;

*** $-\chi^{2}=4,923 ; p=0,027 ;$ ОШ = 0,311; 95\% ДИ 0,108-0,896;

${ }^{* \star \star *}-\chi^{2}=4,923 ; p=0,027 ;$ ОШ = 3,214 + 0,540; 95\% ДИ 1,116-9,257. 
мужчин и женщин составило 1 : 1,2. Незначительное превалирование распространенности тромбоза среди женщин детородного возраста объясняется такими факторами риска, как беременность, использование контрацептивов и заместительной гормональной терапии [22].

Протромбогенные полиморфные варианты генов гемостаза были диагностированы в 94\% случаев. Чаще всего наблюдали полиморфные варианты гена PAl-1 (с.5G6754G), белок которого участвует в регуляции фибринолиза. Наличие полиморфного варианта этого гена приводит к повышению функциональной активности белка ингибитора активатора плазминогена, что в свою очередь способствует повышению риска развития тромбоза [23]. Частота встречаемости гетерозиготного состояния аллеля 4G в -675 положении гена PAl-1 в популяции составляет $50 \%$, гомозиготного состояния - 26\% [24]. В нашей работе аллель 4G в -675 положении гена PAl-1 выявлен в гетерозиготном состоянии (5G/4G) в 57,1\% случаев, в гомозиготном состоянии (4G/4G) - в 22,4\% случаев.

Для гена PAl-1 статистически значимые различия между группой больных ТЦВС и группой здоровых лиц наблюдали в распределении как аллелей, так и генотипов. У пациентов, имеющих генотип 4G/4G, риск развития ТЦВС увеличивается в 10,1 раз (ОШ = 10,132; 95\% ДИ 1,243-82,573), и имеющих генотип 5G/4G - в 3,03 раза (ОШ = 3,030; 95\% ДИ - 1,223-7,507).

Влияние фактора FXIIIA1 на развитие ТЦВС остается не ясным [25]. Возможно, что полиморфизм G103T гена FXIIIA1 сопровождается изменениями в структуре фибрина. При низкой концентрации фрибриногена плотность тромба при полиморфизме G103T высокая, тогда как при повышении уровня фибриногена плотность тромба, и, следовательно, его устойчивость снижаются. При наличии полиморфизма 4G/4G гена PAI-1 протективный эффект полиморфизма G103T гена FXIIIA1 резко снижается [26].

Некоторые авторы отмечают взаимосвязь между полиморфизмом C677T гена MTHFR и риском развития ТЦВС $[27,28]$. В проведенном исследовании протромбогенные полиморфные варианты генов метионингомоцистеинового обмена были диагностированы у 86\% пациентов. Чаще всего встречались полиморфные варианты генов MTRR (с.A66G) и MTR (A2756G). Частота аллеля 66G гена MTRR в европейской популяции, по данным литературы, достигает 54\%, в проведенном исследовании частота его составила - 31,5\%. Аллель G полиморфизма A66G гена MTRR увеличивают риск развития ТЦВС в 3,68 раза (ОШ = 3,683; 95\% ДИ - 1,5648,672), аллель G полиморфизма A2756G гена MTR — в 2,676 раза (ОШ = 2,676; 95\% ДИ - 1,002-7,142) Носительство полиморфизма $A / G$ гена MTRR повышает риск развития ТЦВС в 3,5 раза (ОШ = 3,519; 95\% ДИ - 1,225-10,104), полиморфизма A/G гена MTR в 3,2 раза (ОШ = 3,214; 95\% ДИ - 1,116-9,257).

\section{ВЫВОДы}

Носительство полиморфизма генов PAl-1 (5G6754G), FXIIIA1 (G103T), MTRR (A66G) и MTR (A2756G) повышает риск развития асептического ТЦВС и не влияет на клинические проявления тромбоза.

\section{Литература}

1. Behrouzi R, Punter M. Diagnosis and management of cerebral venous thrombosis. Clin Med (Lond). 2018; 18 (1): 75-9. DOI: 10.7861/clinmedicine.18-1-75

2. Maali L, Khan S, Qeadan F, Ismail M, Ramaswamy D, Hedna VS. Cerebral venous thrombosis: continental disparities. Neurol Sci. 2017; 38 (11): 1963-8. PubMed PMID: 28808795. DOI: 10.1007/ s10072-017-3082-7.

3. Lee DJ, Ahmadpour A, Binyamin T, Dahlin BC, Shahlaie K, Waldau B. Management and outcome of spontaneous cerebral venous sinus thrombosis in a 5 -year consecutive single-institution cohort. J Neurointerv Surg. 2017; 9 (1): 34-8. DOI: 10.1136/ neurintsurg-2015-012237.

4. Agrawal K, Burger K, Rothrock JF. Cerebral sinus thrombosis. Headache. 2016; 56 (8): 1380-9. DOI: 10.1111/head.12873.

5. Capecchi M, Abbattista M, Martinelli I. Cerebral venous sinus thrombosis. J Thromb Haemost. 2018;16 (10):1918-31. DOI: 10.1111/jth.14210.

6. Coutinho JM, Zuurbier SM, Aramideh M, Stam J. The incidence of cerebral venous thrombosis: a cross-sectional study. Stroke. 2012; 43 (12): 3375-7. PubMed PMID: 22996960. DOI: 10.1161/ STROKEAHA.112.671453.

7. Janghorbani $M$, Zare M, Saadatnia M, Mousavi SA, Mojarrad M, Asgari E. Cerebral vein and dural sinus thrombosis in adults in Isfahan, Iran: frequency and seasonal variation. Acta Neurol Scand. 2008; 117 (2): 117-21. PubMed PMID: 18184347. DOI: 10.1111/j.1600-0404.2007.00915.x.

8. Coutinho JM, Zuurbier SM, Stam J. Declining mortality in cerebral venous thrombosis: a systematic review. Stroke. 2014; 45 (5): 1338-41. DOI: 10.1161/STROKEAHA.113.004666.

9. de Freitas GR, Bogousslavsky J. Risk factors of cerebral vein and sinus thrombosis. Front Neurol Neurosci. 2008; (23): 23-54.

10. Kashkoush Al, Ma H, Agarwal N, Panczykowski D, Tonetti D,

Weiner GM, et al. Cerebral venous sinus thrombosis in pregnancy and puerperium: A pooled, systematic review. J Clin Neurosci. 2017; (39): 9-15. DOl: 10.1016/j.jocn.2017.02.046.

11. Bushnell C, McCullough LD, Awad IA, Chireau MV, Fedder WN, Furie $\mathrm{KL}$, et al. Guidelines for the prevention of stroke in women: a statement for healthcare professionals from the American Heart Association/American Stroke Association. Stroke. 2014; 45 (5): 1545-88. DOI: 10.1161/01.str.0000442009.06663.48.

12. Ilyas A, Chen CJ, Raper DM, Ding D, Buell T, Mastorakos P, et al. Endovascular mechanical thrombectomy for cerebral venous sinus thrombosis: a systematic review. J Neurointerv Surg. 2017; 9 (11):1086-92. DOI: 10.1136/neurintsurg-2016-012938.

13. McBane RD, Tafur A, Wysokinski WE. Acquired and congenital risk factors associated with cerebral venous sinus thrombosis. Thromb Res. 2010; 126 (2): 81-7. DOI: 10.1016/j.thromres.2010.04.015.

14. Martinelli I, Cattaneo M, Taioli E, De Stefano V, Chiusolo P, Mannucci PM. Genetic risk factors for superficial vein thrombosis. Thromb Haemost. 1999; 82 (4): 1215-7. PMID: 10544900.

15. Bushnell C, Saposnik G. Evaluation and management of cerebral venous thrombosis. Continuum (Minneap Minn). 2014; 20 (2 Cerebrovascular Disease): 335-51. DOI: 10.1212/01. CON.0000446105.67173.a8.

16. Marjot T, Yadav S, Hasan N, Bentley P, Sharma P. Genes associated with adult cerebral venous thrombosis. Stroke. 2011; 42 (4): 913-8. DOI: 10.1161/STROKEAHA.110.602672.

17. Ferro JM, Bousser MG, Canhão P, Coutinho JM, Crassard I, Dentali $F$, et al. European Stroke Organization guideline for the diagnosis and treatment of cerebral venous thrombosis Endorsed by the European Academy of Neurology. Eur Stroke J. 2017; 2 (3): 195-221. DOI: 10.1177/2396987317719364.

18. Alshoabi SA. Cerebral venous sinus thrombosis: a diagnostic challenge in a rare presentation. Brain Circ. 2017; 3 (4): 227-230. 
DOI: 10.4103/bc.bc_27_17.

19. Gao L, Xu W, Li T, Yu X, Cao S, Xu H, et al. Accuracy of magnetic resonance venography in diagnosing cerebral venous sinus thrombosis. Thromb Res. 2018; (167): 64-73. DOI: 10.1016/j. thromres.2018.05.012

20. Goyal G, Charan A, Singh R. Clinical Presentation, Neuroimaging Findings, and Predictors of Brain Parenchymal Lesions in Cerebra Vein and Dural Sinus Thrombosis: A Retrospective Study. Ann Indian Acad Neurol. 2018; 21 (3): 203-8. DOI: 10.4103/aian.AIAN_470_17.

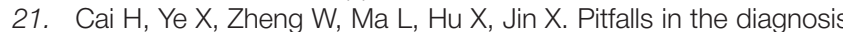
and initial management of acute cerebral venous thrombosis. Rev Cardiovasc Med. 2018; 19 (4): 129-33. DOI: 10.31083/j. rcm.2018.04.4081.

22. Ferro JM, Canhão P, Aguiar de Sousa D. Cerebral Venous Thrombosis. Presse Med. 2016; 45 (12 Pt 2): e429-e450. PubMed PMID: 27816347. DOI: 10.1016/j.Ipm.2016.10.007.

23. Schneider S, Kapelushnik J, Kraus M, El Saied S, Levi I, Kaplan DM The association between otogenic lateral sinus thrombosis and thrombophilia - A long-term follow-up. Am J Otolaryngol. 2018; 39 (3): 299-302. PubMed PMID: 29530427. DOI: 10.1016/j. amjoto.2018.03.013.

\section{References}

1. Behrouzi R, Punter M. Diagnosis and management of cerebral venous thrombosis. Clin Med (Lond). 2018; 18 (1): 75-9. DOl: 10.7861/clinmedicine.18-1-75.

2. Maali L, Khan S, Qeadan F, Ismail M, Ramaswamy D, Hedna VS Cerebral venous thrombosis: continental disparities. Neurol Sci. 2017; 38 (11): 1963-8. PubMed PMID: 28808795. DOI: 10.1007/ s10072-017-3082-7

3. Lee DJ, Ahmadpour A, Binyamin T, Dahlin BC, Shahlaie K, Waldau B. Management and outcome of spontaneous cerebral venous sinus thrombosis in a 5-year consecutive single-institution cohort. J Neurointerv Surg. 2017; 9 (1): 34-8. DOI: 10.1136/ neurintsurg-2015-012237.

4. Agrawal K, Burger K, Rothrock JF. Cerebral sinus thrombosis Headache. 2016; 56 (8): 1380-9. DOI: 10.1111/head.12873.

5. Capecchi M, Abbattista M, Martinelli I. Cerebral venous sinus thrombosis. J Thromb Haemost. 2018;16 (10):1918-31. DOl: 10.1111/jth.14210.

6. Coutinho JM, Zuurbier SM, Aramideh M, Stam J. The incidence of cerebral venous thrombosis: a cross-sectional study. Stroke. 2012; 43 (12): 3375-7. PubMed PMID: 22996960. DOI: 10.1161/ STROKEAHA.112.671453.

7. Janghorbani M, Zare M, Saadatnia M, Mousavi SA, Mojarrad M, Asgari E. Cerebral vein and dural sinus thrombosis in adults in Isfahan, Iran: frequency and seasonal variation. Acta Neurol Scand. 2008; 117 (2): 117-21. PubMed PMID: 18184347. DOI: 10.1111/j.1600-0404.2007.00915.x.

8. Coutinho JM, Zuurbier SM, Stam J. Declining mortality in cerebral venous thrombosis: a systematic review. Stroke. 2014; 45 (5): 1338-41. DOI: 10.1161/STROKEAHA.113.004666.

9. de Freitas GR, Bogousslavsky J. Risk factors of cerebral vein and sinus thrombosis. Front Neurol Neurosci. 2008; (23): 23-54.

10. Kashkoush Al, Ma H, Agarwal N, Panczykowski D, Tonetti D, Weiner GM, et al. Cerebral venous sinus thrombosis in pregnancy and puerperium: A pooled, systematic review. J Clin Neurosci. 2017; (39): 9-15. DOl: 10.1016/j.jocn.2017.02.046

11. Bushnell C, McCullough LD, Awad IA, Chireau MV, Fedder WN Furie $\mathrm{KL}$, et al. Guidelines for the prevention of stroke in women: a statement for healthcare professionals from the American Heart Association/American Stroke Association. Stroke. 2014; 45 (5): 1545-88. DOl: 10.1161/01.str.0000442009.06663.48.

12. Ilyas A, Chen CJ, Raper DM, Ding D, Buell T, Mastorakos P, et al. Endovascular mechanical thrombectomy for cerebral venous sinus thrombosis: a systematic review. J Neurointerv Surg. 2017; 9 (11):1086-92. DOI: 10.1136/neurintsurg-2016-012938.

13. McBane RD, Tafur A, Wysokinski WE. Acquired and congenital risk factors associated with cerebral venous sinus thrombosis. Thromb Res. 2010; 126 (2): 81-7. DOI: 10.1016/j.thromres.2010.04.015.
24. Lichy C, Dong-Si T, Reuner K, Genius J, Rickmann H, Hampe T, et al. Risk of cerebral venous thrombosis and novel gene polymorphisms of the coagulation and fibrinolytic systems. $J$ Neurol. 2006; 253 (3): 316-20. PubMed PMID: 16155788. DOI: 10.1007/s00415-005-0988-4.

25. Li B, Heldner MR, Arnold M, Coutinho JM, Zuurbier SM, Meijers JCM, et al. Coagulation Factor XIII in Cerebral Venous Thrombosis. TH Open. 2019; 3 (3): e227-e229. DOI: 10.1055/s0039-1693487.

26. Bagoly Z, Muszbek L. Factor XIII: What does it look like? J Thromb Haemost. 2019; 17 (5): 714-6. DOI: 10.1111/jth.14431.

27. Ali Z, Troncoso JC, Fowler DR. Recurrent cerebral venous thrombosis associated with heterozygote methylenetetrahydrofolate reductase C677T mutation and sickle cell trait without homocysteinemia: an autopsy case report and review of literature. Forensic Sci Int. 2014; (242): e52-e55. DOI: 10.1016/j.forsciint.2014.07.007.

28. Ghaznavi H, Soheili Z, Samiei S, Soltanpour MS. Association study of methylenetetrahydrofolate reductase C677T mutation with cerebral venous thrombosis in an Iranian population. Blood Coagul Fibrinolysis. 2015; 26 (8): 869-73. DOl: 10.1097/ MBC.0000000000000292.

14. Martinelli I, Cattaneo M, Taioli E, De Stefano V, Chiusolo P, Mannucci PM. Genetic risk factors for superficial vein thrombosis. Thromb Haemost. 1999; 82 (4): 1215-7. PMID: 10544900.

15. Bushnell C, Saposnik G. Evaluation and management of cerebral venous thrombosis. Continuum (Minneap Minn). 2014; 20 (2 Cerebrovascular Disease): 335-51. DOI: 10.1212/01. CON.0000446105.67173.a8.

16. Marjot T, Yadav S, Hasan N, Bentley P, Sharma P. Genes associated with adult cerebral venous thrombosis. Stroke. 2011; 42 (4): 913-8. DOI: 10.1161/STROKEAHA.110.602672.

17. Ferro JM, Bousser MG, Canhão P, Coutinho JM, Crassard I, Dentali $F$, et al. European Stroke Organization guideline for the diagnosis and treatment of cerebral venous thrombosis Endorsed by the European Academy of Neurology. Eur Stroke J. 2017; 2 (3): 195-221. DOI: 10.1177/2396987317719364.

18. Alshoabi SA. Cerebral venous sinus thrombosis: a diagnostic challenge in a rare presentation. Brain Circ. 2017; 3 (4): 227-230. DOI: 10.4103/bc.bc 27 17.

19. Gao L, Xu W, Li T, Yu X, Cao S, Xu H, et al. Accuracy of magnetic resonance venography in diagnosing cerebral venous sinus thrombosis. Thromb Res. 2018; (167): 64-73. DOI: 10.1016/j. thromres.2018.05.012.

20. Goyal G, Charan A, Singh R. Clinical Presentation, Neuroimaging Findings, and Predictors of Brain Parenchymal Lesions in Cerebral Vein and Dural Sinus Thrombosis: A Retrospective Study. Ann Indian Acad Neurol. 2018; 21 (3): 203-8. DOI: 10.4103/aian. AIAN 47017.

21. Cai $H$, Ye X, Zheng W, Ma L, Hu X, Jin X. Pitfalls in the diagnosis and initial management of acute cerebral venous thrombosis. Rev Cardiovasc Med. 2018; 19 (4): 129-33. DOI: 10.31083/j. rcm.2018.04.4081.

22. Ferro JM, Canhão P, Aguiar de Sousa D. Cerebral Venous Thrombosis. Presse Med. 2016; 45 (12 Pt 2): e429-e450. PubMed PMID: 27816347. DOI: 10.1016/.I.lpm.2016.10.007.

23. Schneider S, Kapelushnik J, Kraus M, El Saied S, Levi I, Kaplan DM. The association between otogenic lateral sinus thrombosis and thrombophilia - A long-term follow-up. Am J Otolaryngol. 2018; 39 (3): 299-302. PubMed PMID: 29530427. DOI: 10.1016/j. amjoto.2018.03.013.

24. Lichy C, Dong-Si T, Reuner K, Genius J, Rickmann H, Hampe T, et al. Risk of cerebral venous thrombosis and novel gene polymorphisms of the coagulation and fibrinolytic systems. J Neurol. 2006; 253 (3): 316-20. PubMed PMID: 16155788. DOI: 10.1007/s00415-005-0988-4.

25. Li B, Heldner MR, Arnold M, Coutinho JM, Zuurbier SM, Meijers JCM, et al. Coagulation Factor XIII in Cerebral Venous Thrombosis. TH Open. 2019; 3 (3): e227-e229. DOI: 10.1055/s-0039-1693487. 
26. Bagoly Z, Muszbek L. Factor XIII: What does it look like? J Thromb Haemost. 2019; 17 (5): 714-6. DOI: 10.1111/jth.14431.

27. Ali Z, Troncoso JC, Fowler DR. Recurrent cerebral venous thrombosis associated with heterozygote methylenetetrahydrofolate reductase C677T mutation and sickle cell trait without homocysteinemia: an autopsy case report and review of literature. Forensic Sci Int. 2014;
(242): e52-e55. DOI: 10.1016/j.forsciint.2014.07.007.

28. Ghaznavi H, Soheili Z, Samiei S, Soltanpour MS. Association study of methylenetetrahydrofolate reductase C677T mutation with cerebral venous thrombosis in an Iranian population. Blood Coagul Fibrinolysis. 2015; 26 (8): 869-73. DOI: 10.1097/ MBC.0000000000000292. 